\title{
Physician distribution and attrition in the public health sector of Ethiopia
}

\author{
This article was published in the following Dove Press journal: \\ Risk Management and Healthcare Policy \\ 7 December 2016 \\ Number of times this article has been viewed
}

\section{Tsion Assefa' \\ Damen Haile Mariam' \\ Wubegzier Mekonnen' \\ Miliard Derbew ${ }^{2}$ \\ Wendimagegn Enbiale ${ }^{3}$}

'School of Public Health, ${ }^{2}$ School of Medicine, Addis Ababa University, Addis Ababa, ${ }^{3}$ College of Medicine and Health Science, Bahir Dar University, Bahir Dar, Ethiopia
Correspondence: Tsion Assefa School of Public Health, Addis Ababa University, PO Box 9086, Addis Ababa, Ethiopia

Email tsionassefa2I@yahoo.com
Background: Shortages and imbalances in physician workforce distribution between urban and rural and among the different regions in Ethiopia are enormous. However, with the recent rapid expansion in medical education training, it is expected that the country can make progress in physician workforce supply. Therefore, the aim of this study was to examine the distribution of physician workforce in Ethiopia and assess the role of retention mechanisms in the reduction of physician migration from the public health sector of Ethiopia.

Methods: This organizational survey examined physician workforce data from 119 hospitals from 5 regions (Amhara, Oromia, Southern Nations Nationalities and Peoples Region [SNNPR], Tigray, and Harari) and 2 city administrations (Addis Ababa and Dire Dawa City). Training opportunity, distribution, and turnover between September 2009 and July 2015 were analyzed descriptively. Poisson regression model was used to find the association of different covariates with physician turnover.

Results: There were 2,300 medical doctors in 5 regions and 2 city administrations in $\sim 6$ years of observations. Of these, 553 (24.04\%) medical doctors moved out of their duty stations and the remaining 1,747 (75.96\%) were working actively. Of the actively working, the majority of the medical doctors, 1,407 (80.5\%), were males, in which 889 (50.9\%) were born after the year 1985, 997 (57\%) had work experience of $<3$ years, and most, 1,471 (84.2\%), were general practitioners. Within the observation period, physician turnover among specialists ranged from 21.4\% in Dire Dawa to $43.3 \%$ in Amhara region. The capital, Addis Ababa, was the place of destination for $32(82 \%)$ of the physicians who moved out to other regions from elsewhere in the country. The Poisson regression model revealed a decreased incidence of turnover among physicians born between the years 1975 and 1985 (incident rate ratio [IRR]: 0.63; 95\% confidence interval [CI]: $0.51,0.79$ ) and among those who were born prior to 1975 (IRR: $0.24 ; 95 \%$ CI: $0.17,0.34$ ) compared to those who were born after 1985. Female physicians were 1.4 times (IRR: $1.44 ; 95 \%$ CI: $1.14,1.81)$ more likely to move out from their duty stations compared to males. In addition, physicians working in district hospitals were 2 times (IRR: 2.14; 95\% CI: $1.59,2.89)$ more likely to move out and those working in general hospitals had 1.39 times (IRR: $1.39 ; 95 \%$ CI: 1.08, 1.78) increased rate of turnover in comparison with those who were working in referral hospitals. Physicians working in the Amhara region had 2 times (IRR: 2.01; $95 \%$ CI: $1.49,2.73$ ) increased risk of turnover in comparison with those who were working in the capital, Addis Ababa. The probability of migration did not show a statistically significant difference in all other regions $(P>0.05)$.

Conclusion: The public health sector physician workforce largely constituted of male physicians, young and less experienced. High turnover rate among females, the young and less experienced physicians, and those working in distant places (district hospitals) indicate the need for special attention in devising human resources management and retention strategies.

Keywords: health workforce, physician retention, physician turnover/migration/attrition 


\section{Background}

Health workforce (one of the building blocks of the health system) determines the health system performance and its effectiveness to achieve community health needs. ${ }^{1,2}$ However, many sub-Saharan African countries, including Ethiopia, have weak strategies to retain their health workforce. ${ }^{3,4}$ In Ethiopia, physicians density to population ratio is very low. ${ }^{5,6}$ Imbalances in professional skill mix, variations in distribution between urban and rural places, and among the regions are enormous. ${ }^{5-7}$

Human Resources for Health (HRH) has been continued as global agenda over the years. ${ }^{89} \mathrm{~A}$ number of international initiatives (including developing policy and global code of practice on international recruitment) were attempted to reduce international migration of health care workers from low-income to high-income countries. ${ }^{10,11}$ In addition, enormous efforts have been done to assist the health system of many developing countries. Task shifting through excess supply of low- and mid-level health professionals along with health sector development plans acts as ways of overcoming the problem. Nevertheless, as evidences show, such strategies might play insufficient role either in health service provi$\operatorname{sion}^{12,13}$ or in professional mix (eg, in Ethiopia, low- and mid-level professionals constituted the large majority of the national health workforce). ${ }^{5}$

Health service is a product of the existing health human resources, along with other critical requirements. As a result, inequalities in health care access and outcomes among the nations, between urban and rural populations, and among the regions may reflect the situation better with the presence of imbalanced distribution in qualified health care workers. ${ }^{5,14,15}$ Such imbalances usually manifest in terms of low life expectancy at birth, high maternal mortality, infant and child mortality, and variation in health service utilization and health service quality. ${ }^{15}$

More recently, in cognizant to the need of highly qualified health professionals across the regions, Ethiopia has made rapid expansion in medical education training to increase the supply in physician workforce. ${ }^{16,17}$ In addition, the most recent 2015 Health Sector Transformation Plan (HSTP) of the country indicates the clinical service delivery to be "compassionate, respectful, and with high quality of care," ${ }^{13}$ which may depend not only on the access, availability of physicians, and using regulatory schemes ${ }^{5}$ but also on workforce issues, professional lifestyle, satisfaction, and stay in their duty stations; hence, health service is personal in nature. ${ }^{18,19}$

However, reasons for mal-distribution and challenges for retaining health workforce in the public health sector (particu- larly in rural and remote areas) have become evident. ${ }^{18}$ Large body of literature has documented the critical role of skilled, motivated, and balanced human resources for achieving population health goals (the direct link between skilled human resources and population health outcomes). ${ }^{20}$ However, this is highly dependent on several interlinked factors. First, on the clear HRH policy and uniform strategy for health workforce development. ${ }^{12,21}$ Second, on the ability of the health system for retaining and managing migration to reduce inefficient loss of human resources. ${ }^{22,23}$ Third, on the functioning of human resource information system (to understand the inflows and outflows). ${ }^{24}$ And lastly on the factors that affect the decisions of health workers to work in rural and remote settings. ${ }^{18}$ Health system in many developing countries including Ethiopia, however, lack these important components of HRH to deliver essential health interventions. ${ }^{25,26}$

In Ethiopia, recently, the presence of slight improvement in physician workforce distribution was reported. ${ }^{27} \mathrm{In}$ addition, with the current rapid trend in medical education expansion and supply, the country could make promising improvement in physician workforce, when proper retention mechanisms and balanced distribution work together. However, only limited evidences are available in this regard to understand the progress in physician workforce distribution (following the rapid expansion in medical education), and the role of retention mechanisms to reduce migration from the public health facilities across the regions. Therefore, this study aimed to investigate the distribution and attrition of physician workforce in the public health facilities of Ethiopia.

\section{Methods}

This physician workforce organizational survey was conducted in 5 regions (Amhara, Oromia, Southern Nations Nationalities and Peoples Region (SNNPR), Tigray, and Harari) and 2 city administrations (Addis Ababa and Dire Dawa City Administrations) of Ethiopia. The survey was conducted between February and July, 2015. However, data for Somali Region of Ethiopia were excluded because they were not complete. Overall, the study gathered information on physician workforce from 119 hospitals (19 referral, 46 general, and 54 district hospitals) which were under the auspices of regional health and city administration health bureaus. Five hospital from Addis Ababa (1 referral and 4 general), 20 from Amhara (6 referral, 10 general, and 4 district), 1 referral hospital from Dire Dawa, 63 hospitals from Oromia (5 referral, 18 general, and 40 district), 17 from SNNPR (3 referral, 6 general and 8 district), and 11 from Tigray ( 2 referral, 7 general, and 2 district) were covered by this study. 


\section{Data}

During the initial phases of the present study, the human resources information system at the Federal Ministry of Health was on the process of establishment. As a result, data for the present analysis were collected from the human resource departments of regional health bureaus and hospitals found within the study locality.

In Oromia, Harari, Tigray, SNNPR, and Somali regions of Ethiopia, the required data on physician workforce were obtained via excel spread sheets from the human resource (HR) departments of the respective regional health bureaus. However, in Amhara Region and Addis Ababa and Dire Dawa City Administrations, the data were received in excel speared sheets from each of the hospital HR department through the support of regional health bureau HR departments. Furthermore, in the absence of such organized data (in excel spread sheet), the data were also collected from accessible documents from archives. In Addis Ababa, data were collected from the HR department of 5 hospitals (namely Zewditu Memorial, Ras Desta Damtew Memorial, Menelik II Memorial, Yekatit 12, and Tirunesh Beijing). Data could not be accessed from Gandhi Memorial and Dire Dawa Sabian Hospitals within the study period. In addition, the data for Somali Region were excluded because they were incomplete. Similarly, in SNNPR and Tigray Regions, data on physicians who were recently hired or deployed as well as those who left for specialty training were not included as they were incomplete. SNNPR data on physician turnover and data on private practicing physicians across the regions remains unavailable for the present analysis.

\section{Data collection}

The data were collected on 3 important elements of the physician workforce: distribution, training opportunity, and turnover between September 2009 and July, 2015. Within the study organizations, data were collected by individuals who were working as human resource information system officers and/or data clerks using the local languages in which the study facilities were using to record the data.

\section{Study variables}

The study variables were socio-demographic (date of birth and gender), date of employment, field of specialty and subspecialty of the medical doctors, and information on training opportunity. However, other demographic variables such as marital status and ethnicity were incomplete in most places. In addition, the outcome variable of the study is "physician attrition" which indicates a transition made (in the form of official resignation/dismissal, transfer, retirement, or death) by a physician after taking up an appointment within the time of interest (between September 2009 and July 2015).

\section{Operational definitions}

- Actively working physicians: those physicians who were working in the public health care settings during the data collection period.

- General practitioner (GP): one who completed undergraduate medical education program.

- Specialist: one who completed medical education in a certain areas of medical specialty (such as internal medicine, surgery, pediatrics, gynecology and obstetrics, and so on) after being trained/having served as a GP.

- Subspecialist: one who received training in certain subspecialty area after being trained/having served as a GP and/or specialist.

- Duration of stay/service:

- For actively working physicians, duration of stay/ service years in the assigned place is calculated by subtracting the date of employment from the date of data collection.

- For those who left appointment duration of stay is calculated using the date of departure.

- For those with unknown dates of attrition, service year was subtracted from the date of data collection.

\section{Data management}

Data management and processing involved data organization, data cleaning, and editing using excel spread sheet. However, time-related data such as date of birth, employment, and date of departure were converted from local calendar (Ethiopian calendar that lags 7 years behind for the months between September and December and 8 years for January to August with date variation ranging from 6 days in August to 11 days in October) to Gregorian calendar. In addition, repeated appointments and turnover events within the study settings were captured using physician's recruitment identification number.

\section{Data analysis}

Data were exported from MS Excel to Stata version $13,{ }^{28}$ using Stat Transfer version 9. Descriptive statistics was used to describe the distribution and attrition of physician workforce. 
Poisson regression model is recommended to count events such as turnover especially when the data fail to satisfy Cox's proportional hazards model assumptions, which is the case in this study. ${ }^{29}$ In the study, the outcome variable of interest, turnover/out-migration is measured in the count of events, which is appropriate to perform Poisson regression model on the data. As a result, Poisson regression model was used to identify factors associated with physician attrition from the public health facilities.

\section{Poisson regression modeling}

In the Poisson regression modeling, the exposure variable is duration of stay/service year (is non-zero integer), which is used as offset variable. In addition, for running the model, the event of interest is coded as " 1 " which indicates the occurrence of the event, turnover (all attrition events excluding retirement and death), and " 0 " indicates event is not occurred, it includes actively working and inevitable events (retirement and death).

For explanatory variables, dummy variables were created for categorical explanatory variables to identify the covariates associated with event turnover. For example, gender was coded as male $=1$ (reference), female $=2$; date of birth is also categorized into 3 (born after 1985 = 1 (reference), between 1975 and $1985=2$, and before $1975=3$; educational level GPs $=1$ (reference) and specialist $/$ subspecialist $=2$; setting referral hospital $=1$ (reference), general hospital $=2$, and district hospital $=3$; and for regional locations, Addis Ababa is chosen as a reference.

Incident rate ratio (IRR) with $95 \%$ confidence interval (CI), and $P$-value $=0.05$ was used as cutoff points to explain the observed statistical differences. Finally, validity of the model was assessed using goodness-of-fit (GOF) test after running Poisson model. Deviance GOF test is $P=0.898$ which indicates that the model is well fitted to Poisson regression assumptions.

\section{Ethical approval}

Primarily, the study received ethical permission from the Institutional Review Board (IRB) of College of Health Sciences, Addis Ababa University (Protocol No.043/14/Sph). The approval from AAU was accepted for conducting the study in Addis Ababa and Dire Dawa city administration health offices, Harari, SNNPR, and Tigray region health bureaus and by the health bureau of Somali region of Ethiopia. In addition, the review board of other regions, Amhara Regional Health Bureau (Protocol No. $m / \mathbf{m} / \mathbf{t} \pi / \mathbf{1} / \mathbf{2 5 0} / \mathbf{0 7}$ ) and Oromiyaa Regional Health Bureau (Protocol No. BEFO/
AHBT/1-8/3789) reviewed the proposal and provided ethical permissions for conducting the study. Permission was obtained from regional health bureaus and city administrations to collect the data. However, because of the nature of the data, they were obtained from the study organizations; partly secondary (attrition data) and the available organizational data through recode review, and individual consent was not required for reviewing the records. ${ }^{30}$ However, the data were used anonymously and kept confidential at all times, analyzed, and reported in aggregate.

\section{Results}

In 5 regions and 2 city administrations, there were 2,300 medical doctors within about 6 years of work experience, of these about 1,747 were actively working physicians (during the study), and the remaining 553 were attritions (536 physicians were moved out of their duty stations, 11 died, and 6 retired).

\section{Actively working physicians}

Of the total 1,747 actively working physicians (during the study), the majority $1,407(80.5 \%)$ were male physicians and the remaining 340 (19.5\%) were female physicians. Younger physicians who were born after 1985 accounted for half of the actively working physician workforce 889 (50.9\%), whereas those who were born between 1975 and 1985 were 493 (28.2\%) and those born prior to 1975 were only 216 (12.4\%). Regarding the work experiences, 997 (57\%) had $<3$ years of work experiences, 334 (19.12\%) had 3-years, $167(9.56 \%)$ had $7-10$ years, $54(3 \%)$ had $11-14$ years, and $161(9.22 \%)$ had $\geq 15$ years of work experiences.

In terms of educational levels, GPs constituted the majority of $1,471(84.2 \%)$ actively working physician workforce, while specialists/subspecialists constituted less than one-fifth, 276 (15.8\%). During the study (excluding SNNPR and Tigray), 279 (19.6\%) physicians have been sent for long-term medical training in different areas of clinical specialty/subspecialties. In terms of service provision in health care settings, more than half, 979 (56.04\%) of the physicians were serving in general hospitals, 474 (27.13\%) were serving in referral hospitals, and few proportion of 275 (15.74\%) were serving in district hospitals (Table 1).

The study assessed physician distribution across the regions in 3 categories (general practitioners, residents/ fellows, and specialists/subspecialists). Of the total, $\sim 696$ (39.8\%) physicians were working in Oromia region, followed by 422 (24.1\%) in Amhara, and 330 (18.9\%) in Addis Ababa. However, in small regions like Harari and Dire Dawa city administration, the number of physicians were relatively 
Table I Distribution of actively working physicians in the public health facilities of Ethiopia, September 2009 to July 2015

\begin{tabular}{|c|c|c|c|}
\hline \multirow[t]{2}{*}{ Variables } & \multirow[t]{2}{*}{ Characteristics } & \multicolumn{2}{|c|}{ Actively working } \\
\hline & & Frequency & Percent \\
\hline \multirow[t]{2}{*}{ Gender } & Male & $\mathrm{I}, 407$ & 80.5 \\
\hline & Female & 340 & 19.5 \\
\hline \multirow[t]{4}{*}{ Date of birth } & After 1985 & 889 & 50.9 \\
\hline & $1975-1985$ & 493 & 28.2 \\
\hline & Before 1975 & 216 & 12.4 \\
\hline & Missing & 149 & 8.5 \\
\hline \multirow[t]{5}{*}{ Service years } & $<3$ & 997 & 57.07 \\
\hline & $3-6$ & 334 & 19.12 \\
\hline & $7-10$ & 167 & 9.56 \\
\hline & $11-14$ & 54 & 3.09 \\
\hline & $\geq 15$ & 161 & 9.22 \\
\hline \multirow[t]{2}{*}{ Educational level } & General practitionars & $\mathrm{I}, 47 \mathrm{I}$ & 84.2 \\
\hline & Specialists/subspecialists & 276 & 15.8 \\
\hline \multirow[t]{4}{*}{ Settings } & Referral hospital & 474 & 27.13 \\
\hline & General hospital & 979 & 56.04 \\
\hline & District hospital & 275 & 15.74 \\
\hline & Health offices & 19 & 1.09 \\
\hline Total of each variable & & $\mathrm{I}, 747$ & 100.0 \\
\hline Position during the & On duty & 1,220 & 81.4 \\
\hline \multirow[t]{2}{*}{ study ${ }^{\mathrm{a}}$} & On training & 279 & 19.6 \\
\hline & Total & 1,499 & 100 \\
\hline
\end{tabular}

Note: ${ }^{2}$ Excluding Southern Nations Nationalities and Peoples Region and Tigray.

small. Compared to big regions (Oromia and Amhara), the proportion of specialists and subspecialists who were serving in the capital Addis Ababa and Dire Dawa city administrations were higher. In Addis Ababa, it was about more than one-fourth, 88 (26.7\%), and in Dire Dawa more than one-third, 11 (37.9\%) of the physician workforce. In big regions like Oromia and Amhara, the proportion of specialists/subspecialists were very low, in Amhara only 59 (13.9\%), in Oromia $\sim 80$ (11.5\%), and in SNNPR 22 (14.6\%) of the actively working physician workforce. In Tigray and
Harari regions, the proportion was $11(14.6 \%)$ and $5(22.5 \%)$ of the physician workforce, respectively. In addition, 139 $(19.9 \%)$ of physician workforce in Oromia, 77 (19.2\%) in Amhara, 57 (17.3\%) in Addis Ababa city administration have been sent for further long-term medical training in various clinical specialty/subspecialty areas (Table 2 ).

\section{Characteristics of physician turnover}

Of the total 553 attrition cases, 536 (96.93\%) physicians were left from their duty stations for various reasons. However, the remaining 17 (3.07\%) physicians were departed because of death and retirement.

Of the total 536 turnover events, the majority of 411 (76.68\%) were males and the remaining 125 (23.3\%) were females. Younger physicians (born after 1985) accounted for $206(38.43 \%)$ of the turnover cases, those who were born between 1975 and 1985 were 187 (34.9\%), and those who were born before 1975 years were 86 (16\%).

In terms of work experience, $330(61.57 \%)$ had $<3$ years of work experiences, 91 (16.98\%) had 3-6 years, 32 (5.97\%) had 7-10 years, $20(3.73 \%)$ had $11-14$ years, and $43(8.0 \%)$ had $\geq 15$ years of work experiences. Likewise, compared to specialists 123 (22.95\%), GPs were contributed for the highest proportion of the turnover, 413 (77.05\%). In terms of health service delivery settings, the majority of 289 (53.92\%) were left from the general hospitals, 103 (19.22\%) from referral hospitals, and remaining $92(17.16 \%)$ were left from the district hospitals (Table 3 ).

The study also examined the reasons of attritions in the study settings. Information was available for $\sim 391(70.7 \%)$ of the cases; however, information was limited for the remaining $162(29.29 \%)$ events. Of 391 of the cases, 228 (41.23\%) were resigned from their duty station for personal reasons, 139 (25.14\%) were transferred, 11 (1.99\%) died, 6 (1.08\%)

Table 2 Physician distributions in various regions using the main categories (GPs, residents, and specialists/subspecialists) in Ethiopia, September 2009 to July 2015

\begin{tabular}{|c|c|c|c|c|c|c|c|c|}
\hline \multirow[t]{2}{*}{ Setting } & \multicolumn{2}{|l|}{ GPs } & \multicolumn{2}{|c|}{ Residents/fellows } & \multicolumn{2}{|c|}{ Specialists/subspecialists } & \multicolumn{2}{|l|}{ Total } \\
\hline & Frequency & Percent & Frequency & Percent & Frequency & Percent & Frequency & Percent \\
\hline \multicolumn{9}{|c|}{ Regional locations } \\
\hline Oromia & 477 & 68.5 & 139 & 19.9 & 80 & 11.5 & 696 & 39.8 \\
\hline Amhara & 286 & 67.8 & 77 & 18.2 & 59 & 13.9 & 422 & 24.1 \\
\hline Addis Ababa & 185 & 56.1 & 57 & 17.3 & 88 & 26.7 & 330 & 18.9 \\
\hline SNNPR & $|5|$ & - & - & - & 22 & 14.6 & 173 & 9.9 \\
\hline Tigray & 64 & - & - & - & II & 14.6 & 75 & 4.3 \\
\hline Dire Dawa & 18 & - & - & - & II & 37.9 & 29 & 1.7 \\
\hline Harari & 15 & - & 2 & - & 5 & 22.5 & 22 & 1.3 \\
\hline Total & 1,196 & 68.5 & - & - & 276 & 15.8 & $\mathrm{I}, 747$ & 100 \\
\hline
\end{tabular}

Note: - indicates information was unavailable.

Abbreviations: GP, general practitioner; SNNPR, Southern Nations Nationalities and Peoples Region. 
Table 3 Characteristics of physicians who moved out of their duty stations ( $n=536$ ), September 2009 to July 2015

\begin{tabular}{llll}
\hline Variables & Characteristics & Frequency & Percent \\
\hline Gender & Male & 41 I & 76.68 \\
Date of birth & Female & 125 & 23.32 \\
& After I985 & 206 & 38.43 \\
& I975-1985 & 187 & 34.89 \\
& Prior I975 & 86 & 16.04 \\
Service years & Missing & 57 & 10.63 \\
& $<3$ & 330 & 61.57 \\
& $3-6$ & 91 & 16.98 \\
& $7-10$ & 32 & 5.97 \\
& II-14 & 20 & 3.73 \\
& $\geq$ I5 & 43 & 8.02 \\
Educational level & General practitioners & 413 & 3.73 \\
& Specialist/subspecialist & 123 & 77.05 \\
& Referral hospital & 103 & 22.95 \\
& General Hospital & 289 & 19.22 \\
& District hospital & 92 & 17.16 \\
& Missing & 52 & 9.70 \\
\hline
\end{tabular}

were deployed to other settings, $6(1.08 \%)$ retired, and 1 was dismissed because of discipline. However, of the remaining $162(29.29 \%)$ events, some 92 (16.64\%) left without letting the office know their absence, 57 (10.31\%) did not specify their reasons, and $13(2.35 \%)$ of the cases were not recognized by the HR departments (Figure1).

Figure 2 compares the proportion of specialists/subspecialists who were actively working (during the study) with those who moved out of their duty stations across the regions. Of the total 536 physicians who left from their duty stations, $123(22.9 \%)$ were specialists. Of these 123 specialists, 45 (43.27\%) of the turnover cases were in Amhara region, 38
(30.16\%) in Addis Ababa City Administration Health Bureau, 27 (25.23\%) in Oromia, 6 (35.29\%) in Tigray, $4(44.44 \%)$ in Harari, and $3(21.43 \%)$ in Dire Dawa city administrations.

\section{Repeated turnover events}

Of the total 536 turnover events, 131 (24.44\%) had more than 1 appointments. Of these repeated cases, 99 (75.57\%) were males and the remaining were females. In terms of educational levels, initially $111(84.73 \%)$ were GPs and the remaining $20(15.27 \%)$ were specialists. However, in the second appointments, the educational level improved in some of the cases and the number of specialists were increased from 20 to 31 (25.19\%) and the number of GPs decreased to 98 (74.81\%). In addition, 93 (70.99\%) of the physicians went to similar health care settings (to the public health sector), whereas 37 (29.01\%) went to the academic positions (medical schools). Of those who went to public health sector, $54(58.06 \%)$ went to the same regions, while $39(41.94 \%)$ left to other regions $(-82.05 \%$ come to the capital, Addis Ababa).

Furthermore, the length of stay in between the destinations was come down from one destination to next; initially, the mean duration of stay was 3.4 years ( $95 \%$ CI: $2.66,4.10)$, for next destination it became 1.33 years $(95 \% \mathrm{CI}: 1.12$, $1.55)$ and then it declined to 1.01 years ( $95 \%$ CI: $0.20,1.20)$.

Despite being small in number, whereabouts of physicians in the second destination were 3 physicians shift to the academics, 8 to other regions ( 5 to different regions, 2 to Addis Ababa, and 3 moved out of Addis), and 3 to same regions. However, no information was found for $\sim 20$ of the cases within the study settings (Table 4).

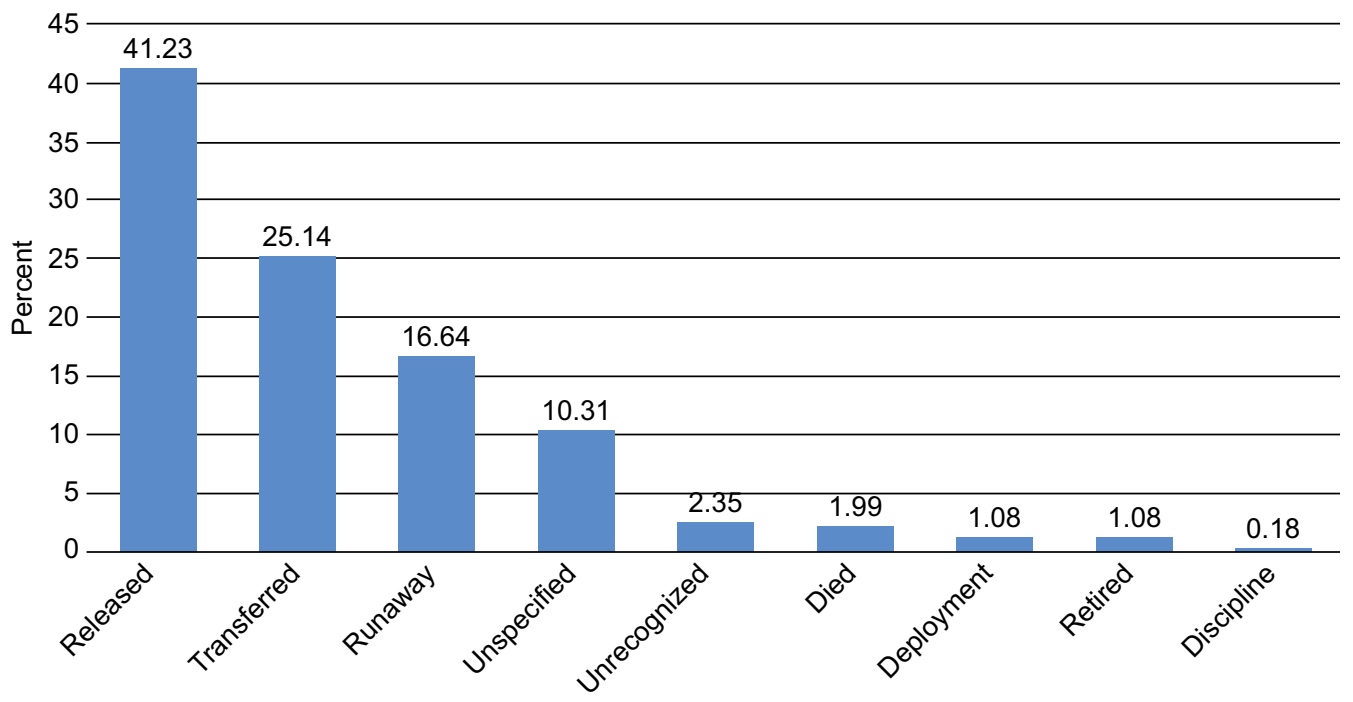

Figure I Reasons for attritions for physicians who left their appointments in percent, September 2009 to July 2015. 


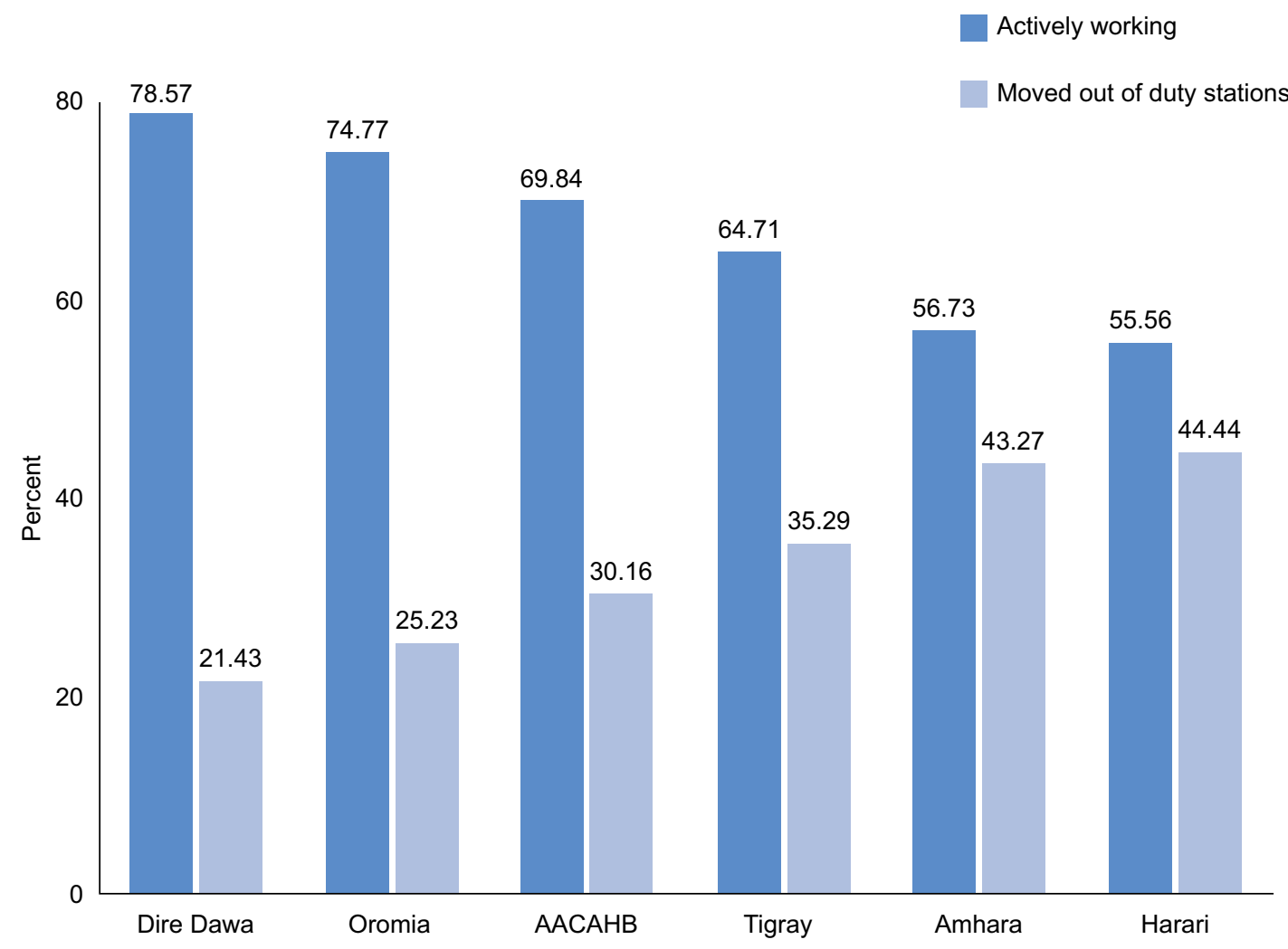

Figure 2 Comparisons between specialists who were actively working (during the study) and those who moved out of their duty stations across the regions in percent, September 2009 to July 2015.

Abbreviation: AACAHB, Addis Ababa City Administration Health Bureau.

\section{Factors associated with physician turnover}

Univariate analyses showed the presence of significant $(\alpha<0.05)$ association between physician turnover and their gender, birth year, health service delivery settings, and geographical locations. The Poisson regression model revealed that female physicians were 1.4 times more likely (IRR $=1.44$; $95 \%$ CI: $1.14,1.81)$ to move out from their duty stations compared to their counterparts. On the other hand, as the age of physicians increased, the incidence of physician turnover decreased; the incidence of turnover among physicians born between 1975 and 1985 was $37 \%$ (IRR $=0.63 ; 95 \% \mathrm{CI}$ : $0.51,0.79)$ lower compared to those born after 1985 years. Likewise, the likelihood of turnover among physicians born prior to 1975 was $76 \%$ (IRR $=0.24$; $95 \%$ CI: $0.17,0.34$ ) lower compared to those who were born after 1985 .

In terms of educational levels, GPs had a $31 \%$ increased incidence of turnover compared to specialists/subspecialists (IRR $=1.31 ; 95 \% \mathrm{CI}: 0.99,1.75$ ), and the $\mathrm{CI}$ is marginal and not statistically significant $(P=0.062)$. In addition, turnover variations were observed between health service delivery settings. Compared to physicians working in referral hospitals, those working in the general hospitals were 1.39 times more likely to move out (IRR $=1.39 ; 95 \% \mathrm{CI}: 1.08,1.78)$ from their duty station. Similarly, physicians working in district hospitals had more than 2-fold increased chance of turnover compared with those working in the referral hospitals (IRR $=2.14$; 95\% CI: 1.59, 2.89).

Regarding the turnover risk of physicians across the regions, compared to the capital Addis Ababa, the incidence of physician migration was 2 times higher in Amhara region (IRR $=2.01 ; 95 \%$ CI: 1.49, 2.73), however no statistically significant association has been observed for the remaining regions and city administration $(P>0.05)$ (Table 5$)$.

\section{Discussion}

This study generates important information about the most recent physician workforce distribution and attrition in the public health facilities of Ethiopia through involving 119 hospitals (19 referral hospitals, 46 general hospitals, and 54 district hospitals) in 5 regions and in 2 city administrations. It examined the distribution and attrition of physician workforce including carrier opportunities in further training. The findings of the study suggest the presence of substantial improvement in physician workforce across the regions compared to the last 5 years. ${ }^{27}$ Such information is valuable for making informed decisions for physician workforce planning, physician workforce retention, and health facility expansion and quality service provision in the country. 
Table 4 Characteristics of repeated turnover events between September 2009 and July 2015

\begin{tabular}{|c|c|c|c|}
\hline Variables & Characteristics & Frequency & Percent \\
\hline \multirow[t]{2}{*}{ Gender } & Male & 99 & 75.57 \\
\hline & Female & 32 & 24.43 \\
\hline \multirow[t]{2}{*}{ Educational level } & GPs & III & 84.73 \\
\hline & Specialists & 20 & 15.27 \\
\hline $\begin{array}{l}\text { Duration of stay } \\
\text { in years }\end{array}$ & Mean & \multicolumn{2}{|c|}{3.4 (95\% Cl: $2.66,4.10)$} \\
\hline \multicolumn{4}{|l|}{ Fist destination } \\
\hline \multirow[t]{2}{*}{ Settings } & Clinical & 93 & 70.99 \\
\hline & Academic & 37 & 29.01 \\
\hline \multirow[t]{2}{*}{ Educational levels } & GPs & 98 & 74.81 \\
\hline & Specialists & 31 & 25.19 \\
\hline \multirow[t]{2}{*}{ Place moved $(n=93)$} & To same region & 54 & 58.06 \\
\hline & To different regions & 39 & 41.94 \\
\hline From different & To Addis Ababa & 32 & 82.05 \\
\hline regions $(n=39)$ & Another region & 7 & 17.95 \\
\hline $\begin{array}{l}\text { Duration of stay } \\
\text { in years }\end{array}$ & Mean & \multicolumn{2}{|c|}{ I.33 (95\% Cl: I.I2, I.55) } \\
\hline \multicolumn{4}{|c|}{ Second destination $(n=3 I)$} \\
\hline \multirow[t]{3}{*}{ Settings } & Clinical & \multicolumn{2}{|l|}{8} \\
\hline & Academic & \multicolumn{2}{|l|}{3} \\
\hline & Unknown & \multicolumn{2}{|l|}{20} \\
\hline \multirow[t]{2}{*}{ Place moved } & To same region & \multicolumn{2}{|l|}{3} \\
\hline & To different regions & \multicolumn{2}{|l|}{5} \\
\hline \multirow{3}{*}{$\begin{array}{l}\text { From different } \\
\text { regions }(n=5)\end{array}$} & To Addis Ababa & \multicolumn{2}{|l|}{2} \\
\hline & Out of Addis & \multirow{2}{*}{\multicolumn{2}{|c|}{3}} \\
\hline & Ababa & & \\
\hline $\begin{array}{l}\text { Duration of stay } \\
\text { in years }\end{array}$ & Mean & \multicolumn{2}{|c|}{ I.0I (95\% Cl: $0.20,1.20)$} \\
\hline
\end{tabular}

Abbreviations: GP, general practitioner; $\mathrm{Cl}$, confidence interval.
In this study, the significant proportion of the medical service providers were male physicians, which indicates gender imbalance. ${ }^{7}$ On the contrary, females frequently moved out of their duty stations compared to males. This might be due to personal and family reasons and professional lifestyle factors. ${ }^{18,31}$

Young and less experienced physicians share significant proportion of the public health sector physician workforce of the country. This might imply the presence of increase in physician workforce supply in the country. Nevertheless, the turnover rate was significantly higher among these groups, younger and less experienced because of the deployment of new graduates in remote areas that have poor infrastructure with unsatisfied expectations in incentives and professional lifestyles. ${ }^{19,32}$ Next to economic incentives, the importance of intrinsic motivation and being from rural origin were reported from African countries..$^{33}$ From Japan, population characteristics and medical demand in the population reported to attract physicians. ${ }^{34}$

In this study, more than half of the physician workforce was serving in the general hospitals. However, the incidence of turnover was higher among those physicians who were working in general and district hospitals than those working in referral hospitals. This finding might imply the attention that needs to be given for those who assigned at distant and remote places..$^{35}$ Because previous studies indicated the direct link between physicians access with improved health outcomes, especially from chronic illness (which have been emerging in the country), ${ }^{20}$ and the negative impact of

Table 5 Factors associated with physician turnover: using Poisson regression model between September 2009 and July 2015

\begin{tabular}{|c|c|c|c|c|c|c|}
\hline \multirow[t]{2}{*}{ Variable } & \multirow[t]{2}{*}{ Category } & \multirow[t]{2}{*}{ IRR } & \multirow[t]{2}{*}{ SE } & \multirow[t]{2}{*}{$P$-value } & \multicolumn{2}{|l|}{$95 \% \mathrm{Cl}$} \\
\hline & & & & & Lower & Upper \\
\hline \multirow[t]{2}{*}{ Gender } & Male (reference) & & & & & \\
\hline & Female & $\mathrm{I} .44$ & 0.17 & 0.002 & 1.14 & 1.81 \\
\hline \multirow[t]{3}{*}{ Date of birth } & After 1985 (reference) & & & & & \\
\hline & $1975-1985$ & 0.63 & 0.07 & 0.000 & 0.51 & 0.79 \\
\hline & Before 1975 & 0.24 & 0.04 & 0.000 & 0.17 & 0.34 \\
\hline \multirow[t]{2}{*}{ Educational level } & Specialist/subspecialist (reference) & & & & & \\
\hline & GPs & 1.31 & 0.19 & 0.062 & 0.99 & 1.75 \\
\hline \multirow[t]{3}{*}{ Settings } & Referral hospital (reference) & & & & & \\
\hline & General hospital & 1.39 & 0.18 & 0.008 & 1.08 & 1.78 \\
\hline & District hospital & 2.14 & 0.33 & 0.000 & 1.59 & 2.89 \\
\hline \multirow[t]{6}{*}{ Regional location } & Addis Ababa (reference) & & & & & \\
\hline & Amhara & 2.01 & 0.31 & 0.000 & 1.49 & 2.73 \\
\hline & Dire Dawa & 1.05 & 0.50 & 0.90 & 0.41 & 2.68 \\
\hline & Harari & 0.75 & 0.38 & 0.57 & 0.27 & 2.04 \\
\hline & Oromia & 1.10 & 0.17 & 0.53 & 0.82 & 1.48 \\
\hline & Tigray & 0.60 & 0.18 & 0.10 & 0.34 & 1.10 \\
\hline
\end{tabular}

Abbreviations: GP, general practitioner; $\mathrm{Cl}$, confidence interval; IRR, incident rate ratio; SE, standard error. 
migration; ${ }^{36}$ subsequently, it might result in institutional and service delivery imbalances. ${ }^{7}$

The study also examined turnover reasons, transfer (within the public health sector), and release (might be out of or within the public) were the common types. This might indicate the importance of both the types of migration (internal and external) as both affect the health service delivery. ${ }^{37,38} \mathrm{At}$ the same time, the external migration also has a tendency to exacerbate in-country rural-urban migration, ${ }^{39}$ it may result in mal-distribution of physicians between the regions, and urban-rural settings. ${ }^{12}$

In addition, significant proportion of physicians left uninformed regarding the whereabouts of their duty stations. This findings might imply lack of uniformity in human resource management ${ }^{8,22}$ and lack of functioning human resource information system which is very critical for health workers planning and understanding the loss rate..$^{12,19,40}$

In health service delivery, specialist physicians play critical role in undertaking clinical procedures than the general practitioners. However, compared to GPs proportion of specialists were very few. In addition, the turnover among specialists was $21.4 \%$ in Dire Dawa to $43.3 \%$ in Amhara region. It may suggest that regional disparity and rural-urban migration can potentially affect the clinical service quality and health service provision, ${ }^{7}$ and this finding might highlight the measures that need to be considered on the implementation of the recent HSTP and its achievement (which aimed at compassionate, respectful, and quality of care).

Repeated movement within the study settings might imply physicians' interest to work in the public health sector or unfinished compulsory service years or the presence of vacant places in urban areas. This might be true in the case of specialist as the educational level improved (from GP to specialist), they may have assigned to the next level, which is consistent with the descriptive findings and the regression model, the turnover rate is higher in district hospitals. However, improving benefits and creating conducive work environment might improve the situation, particularly for those who are interested to work in the public health sector because the role of intrinsic and motivational factors are reported in similar study. ${ }^{33}$

Physician migration to the academic medical schools might be another important finding of this study. This might be explained by high demand for medical teachers following the rapid expansion in medical schools in the country. Or it might be due to perceived better working environment than the public health sector or a means to shift from the rural and distant places, as most medical schools are located in urban places.

However, the higher incidence of migration to the capital, Addis Ababa, might be similar to the rural-urban migration as reported in previous studies, ${ }^{6}$ which might result in disparities in service provision, skill transfer, and health outcomes to the large majority of the population who live in the rural parts of Ethiopia. ${ }^{5}$ In addition, the mean duration among physicians who moved out from their duty stations also supports this explanation, as the rate of turnover increased the mean duration of stay in the duty station decreased.

\section{Limitations}

Despite its relevant contribution to human resource development and management in Ethiopia, this study has its own limitations. The available human resource data lack uniformity; the study did not address the performance of physicians and physicians working under the federal ministry of health or academics in the study settings.

\section{Conclusion}

The findings of this study suggest the presence of substantial improvement in physician workforce supply across the regions. However, compared to the size of population and health service demand in the community, there is physician workforce shortages, particularly of that of specialist physicians along with high turnover rates. This situation can potentially affect health care access, service provision, clinical service quality, and its outcomes among the community (potential source of health services inequalities), thus seeking the attention for those who have served their compulsory service years. More importantly, attention needs to be given in dealing with the challenges and opportunities to retain physicians in distant and remote places.

Turnover to the academic settings might also imply the way how the education and public health sector needs to work together. However, the turnover through transfer and release might indicate the presence of internal and external migration, and the external and rapid expansion in medical education might also exacerbate in-country rural-urban migration. On the other hand, physicians who left their duty stations uninformed about the whereabouts might indicate lack of uniformity in human resource management and retention mechanisms.

Finally, HRH data handling needs critical attention and improvement throughout the country. Further research on exploring the reasons for physician turnover and retention strategies that can potentially fit to the local context is recommended. 


\section{Acknowledgments}

The human resource department of all regions and their data clerks are acknowledged for their strong support in data collection and extraction. This research is supported by a grant from Medical Education Initiative Partnership (MEPI) project; Addis Ababa University, Ethiopia.

\section{Author contributions}

TA conducted the study and performed statistical analysis, interpretation of the data, and manuscript writing. DHM supervised the study and performed statistical analysis and manuscript writing. WM supervised the study and assisted in statistical and data analysis and interpretation of the data. MD supervised the study and assisted in interpretation of the data and report writing. WE involved in interpretation of the findings and report writing. All the authors were involved in drafting and revising the manuscript and read and approved the final manuscript.

\section{Author information}

TA is a PhD candidate at the School of Public Health, AAU. DM is a professor of Health Services and Health Policy at the School of Public Health AAU, editor-in-chief for the Ethiopian Journal of Health Development and consultant with Federal Ministry of Health, Ethiopia. WM is an assistant professor in the aforementioned school, statistician, demographer, and public health researcher. MD is an associate professor in the School of Medicine, AAU, pediatrics surgeon, and researcher. WE is an assistant professor at the College of Medicine and Health Science, Bahir Dar University.

\section{Disclosure}

The authors report no conflicts of interest in this work.

\section{References}

1. World Health Organization. Working Together for Health. World Health Report 2006. Available from: www.who.int/whr/2006/whr06_en.pdf. Accessed March 9, 2015.

2. World Health Organization. Everybody business:strengthening health systems to improve health outcomes: WHO's framework for action; 2007, Geneva. Available from: www.who.int/healthsystems/strategy/ everybodys_business.pdf. Accessed April 9, 2015.

3. World Health Organization. Global Atlas of the Health Workforce 2010. Available from: http://www.hrhresourcecenter.org/node/2182. Accessed October 11, 2015.

4. Soucat A, Scheffler R, Ghebreyesus T. The labor market for health workers in Africa: a new look at the crisis. World Bank; 2013. Available from: https://openknowledge.worldbank.org/bitstream/ handle/10986/13824/82557.pdf. Accessed September 29, 2016.

5. World Bank. The Health Workforce in Ethiopia; Addressing the Remaining Challenges. Washington, DC: World Bank; 2012. Available from: http://elibrary.worldbank.org/content/book/9780821389843. Accessed March 5, 2013.
6. Africa Health Workfoce Observatory. Human Resources for Health Country Profile Ethiopia; 2010. Available from: http://www.hrh-observatory.afro.who.int/images/Document_Centre/Country_profile_Ethiopia.pdf. Accessed October 25, 2015.

7. Zurn P, Poz MRD, Stilwell B, Adams O. Imbalance in the health workforce. Hum Resour Health. 2004;2:13.

8. World Health Organization, Global Health Workforce Alliance. Human Resources for Health: foundation for Universal Health Coverage and the post-2015 development agenda. Recife, Brazil 2013. Available from: http://www.who.int/workforcealliance/knowledge/resources/ report3rd_GF_HRH.pdf. Accessed June 9, 2016.

9. World Health Organization. Health workforce and services. Draft global strategy on human resources for health: workforce 2030. Report by the Secretariat. WHO Executive Board; 2015. Available from: http://who. int/hrh/resources/WHO_GSHRH_DRAFT_21Dec15.pdf.

10. World Health Organization. The WHO Global Code of Practice on the International Recruitment of Health Personnel; 2010. Available from: http://www.who.int/hrh/migration/code/WHO_global_code_of_practice_EN.pdf. Accessed October 13, 2015.

11. Hagopian A, Thompson MJ, Fordyce M, Johnson KE, Hart LG. The migration of physicians from sub-Saharan Africa to the United States of America: measures of the African brain drain. Hum Resour Health. 2004;2:17.

12. Girma S, Yohannes GA, Kitaw Y, Ye-Ebiyo Y, Seyoum A, Desta H, Teklehaimanot A. Human resource development for health in Ethiopia: challenges of achieving the millennium development goals. Ethiop $J$ Health Dev. 2007;21(3):216-231.

13. Federal Democratic Republic of Ethiopia Ministry of Health. Health Sector Transformation Plan: 2015/16 - 2019/20; 2015. Available from: http://www.emtct-iatt.org/wp-content/uploads/2016/01/EthiopiaHSSP-2015-2020.pdf. Accessed June 2015.

14. World Health Organization. World Health Statistics: Golobal Health Indicators. Geneva, Switzerland; 2015. Available from: http://apps.who. int/iris/bitstream/10665/170250/1/9789240694439_eng.pdf. Accessed June 3, 2015.

15. Central Statistical Agency [Ethiopia] and ICF International. Ethiopia Mini Demographic and Health Survey 2014. Addis Ababa, Ethiopia. Available from: https://www.unicef.org/ethiopia/Mini_DHS_2014_ Final_Report.pdf. Accessed May 5, 2016.

16. Federal Ministry of Education. Education Statistics Annual Abstract 2012/13. Addis Ababa; 2013. Available from: http://www.moe.gov.et/-/ education-statistics-annual-abstract-2005-e-1?inheritRedirect=true. Accessed September 9, 2015.

17. Federal Ministry of Education. Education Statistics Annual Abstract, 2007 E.C.(2014/15). June/July 2016. Available from: www.moe.gov. et/-/education-statistics-annual-abstract-2007-e-c. Accessed September 2016.

18. Paliadelis PS, Parmenter G, Parker V, Giles M, Higgins I. The challenges confronting clinicians in rural acute care settings: a participatory research project. Rural Remote Health. 2012;12:2017.

19. Mathauer I, Imhoff I. Health worker motivation in Africa: the role of non-financial incentives and human resource management tools. Hum Resour Health. 2006;4:24.

20. Lee J, Park S, Choi K, Kwon S-m. The association between the supply of primary care physicians and population health outcomes in Korea. Fam Med. 2010;42:9:628-635.

21. Dussault G, Dubois CA. Human resources for health policies: a critical component in health policies. Hum Resour Health. 2003;1:1.

22. Pong RW. Strategies to overcome physician shortages in northern Ontario: a study of policy implementation over 35 years. Hum Resour Health. 2008;6:24:1478-4491.

23. Lofters A, Slater M, Fumakia N, Thulien N. "Brain drain" and "brain waste": experiences of international medical graduates in Ontario. Risk Manag Healthcare Policy. 2014;7:81-89.

24. World Health Organization, Global Health Workforce Alliance. The Kampala Declaration and Agenda for Global Action. Geneva: WHO; 2008. Available from: http://www.who.int/workforcealliance/knowledge/resources/kampala_declaration/en/. Accessed July 3, 2015. 
25. World Health Organization. Monitoring the Building Blocks of Health Systems 2010. Available from: http://www.who.int/healthinfo/systems/ WHO_MBHSS_2010_full_web.pdf. Accessed October 27, 2015.

26. World Health Organization. Models and Tools for Health Workforce Planning and Projections 2010. Issue 3. Geneva. Accessed February 23, 2016.

27. Federal Ministry of Health. Health and Health Related Indicators 2005 E.C (2012/2013). Available from: http://www.moh.gov.et/ documents $/ 26765 / 0 /$ Health+and+Health+Related+Indicators $+2005+$ E.C/1b5b2a9f-a960-4024-8d92-519195364023?version=1.0. Accessed December 6, 2015 .

28. StataCorp. Stata: Release 13. Statistical Software. College Station, TX: StataCorp LP; 2013.

29. Hilbe JM. Modeling count data. New York: Cambridge University Press; 2014.

30. FDRE Ministry of Sciences and Technology. National Research Ethics Review Guideline; 2014. Available from: http:/www.ccghr.ca/wpcontent/uploads/2013/11/national-research-ethics-review-guidline.pdf. Accessed September 27, 2016.

31. Vanasse A, Scott S, Courteau J, Orzanco G. Canadian family physicians' intentions to migrate Associated factors. Can Fam Physician. 2009;55:396-340.

32. Barer ML, Stoddart GL. Toward integrated medical resource policies for Canada: Geographic distribution of pysicians. Can Med Assoc J. 1992;148:1.

33. Serneels P, Montalvo JG, Pettersson G, Lievens T, Butera JD, Kidanu A. Who wants to work in a rural health post? The role of intrinsic motivation, rural background and faith-based institutions in Ethiopia and Rwanda. Bull World Health Organ. 2010;88(5): 342-349.
34. Matsumoto M, Inoue K, Noguchi S, Toyokawa S, Kajii E. Community characteristics that attract physicians in Japan: a cross-sectional analysis of community demographic and economic factors. Hum Resour Health. 2009;7:12.

35. Russell DJ. The Patterns, Determinants and Measurement of Rural and Remote Primary Health Care WorkforceTurnover and Retention. School of Rural Health, Faculty of Medicine, Nursing and Health Sciences, Monash University; 2014. Available from: https://www.healthinfonet.ecu.edu.au/key-resources/bibliography/?lid=28766. Accessed October 8, 2016.

36. Grignon M, Owusu Y, Sweetman A. The International Migration of Health Professionals 2012. Discussion Paper No. 6517 Canada Available from: http://www.iza.org/MigrationHandbook/04_Grignon Owusu_Sweetman_The\%20Intern_Migration_of_Health_Professionals.pdf. Accessed May 2016.

37. Sherr K, Mussa A, Chilundo B, Gimbel S, Pfeiffer J, Hagopian A, Gloyd S. Brain drain and health workforce distortions in Mozambique. PLoS One. 1371;7:4.

38. Awases M, Gbary A, Nyoni J, Chatora R. Migration of Health Professionals in Six Countries: A Synthesis Report. WHO Regional Office for Africa. 2004. Available from: http://www.hrhresourcecenter.org/ node/61. Accessed March 4, 2016.

39. Organisation for Economic Co-operation and Development, World Health Organization. International Migration of Health Workers, Policy Brief. 2010. Available from: https:/www.oecd.org/migration/ mig/44783473.pdf. Accessed April 21, 2016.

40. Hastings SE, Armitage GD, Mallinson S, Jackson K, Suter E. Exploring the relationship between governance mechanisms in healthcare and health workforce outcomes: a systematic review. BMC Health Serv Res. 2014;14(479):1472-6963.
Risk Management and Healthcare Policy

\section{Publish your work in this journal}

Risk Management and Healthcare Policy is an international, peer-reviewed open access journal focusing on all aspects of public health, policy, and preventative measures to promote good health and improve morbidity and mortality in the population. The journal welcomes submitted papers covering original research, basic science, clinical and epidemiological

\section{Dovepress}

studies, reviews and evaluations, guidelines, expert opinion and commentary, case reports and extended reports. The manuscript management system is completely online and includes a very quick and fair peerreview system, which is all easy to use. Visit http://www.dovepress.com/ testimonials.php to read real quotes from published authors. 